\title{
Severe hypovitaminosis D in pregnant refugees arriving in Europe: neonatal outcomes and importance of prenatal intervention
}

\author{
Anna Liori' ${ }^{1}$, Damaskini Polychroni ${ }^{1}$, Georgios K Markantes ${ }^{1}$, Maria Stamou ${ }^{1}$, Sarantis Livadas ${ }^{2}$, George Mastorakos ${ }^{3}$ \\ and Neoklis Georgopoulos ${ }^{1}$
}

${ }^{1}$ Division of Endocrinology, Department of Internal Medicine, University of Patras, School of Health Sciences, Patras, Greece

${ }^{2}$ Endocrine Unit, Athens Medical Centre, Athens, Greece

3Unit of Endocrinology, Diabetes Mellitus and Metabolism, Aretaieion Hospital, Medical School, National and Kapodistrian University of Athens,

Athens, Greece

Correspondence should be addressed to N Georgopoulos: neoklisgeorgo@gmail.com

\begin{abstract}
Adequate vitamin D levels are particularly important in pregnant women for both maternal Key Words and neonatal health. Prior studies have shown a significantly high prevalence of vitamin D vitamin D deficiency deficiency (VDD) among refugees. However, no study has addressed the prevalence of VDD $\bullet$ pregnant women in pregnant refugees and its effects on neonatal health. In this study, we examined the $\quad$ refugees prevalence of VDD in refugee pregnant women living in Greece and compared our results with Greek pregnant inhabitants. VDD was frequent in both groups but was significantly more common in refugees (92.2 vs $67.3 \%$ of Greek women, $P=0.003$ ) with $70.6 \%$ of refugees having severe hypovitaminosis $D(<10 \mathrm{ng} / \mathrm{mL})$. As a result, most newborns had VDD, which affected refugee newborns to a greater extent. Our results suggest a need to screen newcomer children and pregnant women for VDD in all host countries around the world. Such a screen will appropriately guide early and effective interventions with the goal to prevent adverse neonatal and maternal outcomes.
\end{abstract}

\section{Introduction}

Vitamin D, an essential fat-soluble vitamin or steroid prohormone, has many physiological roles, as it is not only responsible for the regulation of $\mathrm{Ca}$ and $\mathrm{P}$ homeostasis and bone metabolism (1), but it is also implicated in multiple biological systems such as immunomodulation, cellular proliferation and differentiation; thus, adequate levels are necessary and advantageous for optimal health (1). 25-hydroxyvitamin D (25OHD) is the main vitamin $\mathrm{D}$ metabolite in the circulation. Though there is no consensus on optimal levels of serum 25OHD, vitamin D deficiency (VDD) is defined by most experts as $25 \mathrm{OHD}<20$ $\mathrm{ng} / \mathrm{mL}$, a level of $21-29 \mathrm{ng} / \mathrm{mL}$ is considered to indicate a relative insufficiency, and a level of $30 \mathrm{ng} / \mathrm{mL}$ or greater indicates sufficient vitamin D (2). Humans get vitamin D mostly from exposure to sunlight (90\% of the intake) and only partially from their diet (10\% of intake) (1). Excessive exposure to the sun's UVB radiation can lead to diseases such as skin cancer. On the other hand, lack of adequate exposure to UVB can lead to VDD, as vitamin D is found naturally in only a few foods. Hence, vitamin $\mathrm{D}$ has been added to specific foods and is typically prescribed as tablets around the world with the goal to prevent VDD.

VDD affects more than one billion people globally including children and adults. It can be associated with osteopenia and osteoporosis as well as non-bone-related conditions such as autoimmune diseases and cancer (3, 4). Apart from its necessity for the general population, adequate vitamin D levels in pregnant women are important for several reasons. First, maternal 25OHD crosses the placenta and reaches the fetus (5); after birth, when the

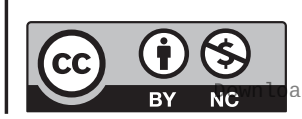


neonate loses the placental nutrient supply, it becomes completely dependent on vitamin D-mediated intestinal absorption of $\mathrm{Ca}$ and phosphate to meet the demands of the developing skeleton (5). Hence, neonatal VDD might lead to hypocalcemia, rickets and impaired bone health in later life (6). Furthermore, gestational VDD has been associated with several adverse obstetric outcomes, such as gestational diabetes mellitus, preeclampsia, intrauterine growth restriction, preterm labor and primary cesarean section as well as adverse outcomes in the offspring later in life $(7,8,9,10)$.

Interestingly, gestational VDD is highly prevalent in countries where prenatal visits are common and the health system is considered developed and even in countries that are characterized by frequent sunlight such as Greece (11, 12). Keeping that in mind, one would consider that such a condition could have even more devastating outcomes in populations that do not have access to prenatal care and have not undergone robust evaluation during pregnancy. In fact, VDD has been described in several groups of immigrants and refugees in different parts of the world (13). To date, no study has investigated the prevalence of VDD in refugees during pregnancy and its association with fetal and neonatal outcomes. Moreover, although prior studies (11) assessing vitamin D status in pregnancy in Greece have included women of other ethnic origins integrated in the Greek society, the vitamin D status of immigrant pregnant women living in refugee camps (and their newborns) has never been evaluated. To answer this question with the goal to identify the best practices to support refugee women undergoing pregnancy and delivery under such difficult conditions, we conducted a study in pregnant women who were residents of the Greek island of Lesvos and refugees who live in refugee camps in the same island. In this study, we evaluated $25 \mathrm{OHD}$, parathyroid hormone (PTH), total Ca and P levels in maternal serum and in cord blood at delivery from Greek women and women living in a refugee camp in the island of Lesbos and explored potential correlations of hormone and mineral levels with anthropometric characteristics of the neonates.

\section{Materials and methods}

\section{Subject recruitment}

We conducted a cross-sectional study of 103 pregnant women, 52 Greek inhabitants of Lesbos and 51 immigrants living in the 'Moria' and the 'Kara Tepe' Refugee Camps in Lesbos, Greece, who gave birth at the Hospital of Lesvos
(Vostaneio) from October 1, 2018, to June 5, 2019. Refugees were recruited only if they had spent at least 6 months in Lesbos prior to delivery. All participants were recruited at delivery, they were healthy and had uncomplicated, term pregnancies. None of the participants was taking medication known to affect $\mathrm{Ca}, \mathrm{P}$, vitamin $\mathrm{D}$ or PTH homeostasis. Greek pregnant women were taking 800 IU of vitamin D daily, whereas refugees were not on any vitamin D supplementation. Maternal age, ethnicity, prior medical and obstetric history, type of delivery and gestational age were recorded for each participant. The sex and anthropometric features (birth weight, length and head circumference) of the newborns were also recorded. All participants provided informed consent prior to enrolment. The study was approved by the Vostaneio Hospital ethical committee.

\section{Laboratory evaluation}

Maternal blood samples were collected by venipuncture on the day of labor, and umbilical cord blood was collected from the umbilical vein immediately after clamping. 25OHD and PTH were analyzed in maternal and cord blood by electrochemiluminescence in Cobas e 411 analyzer (Roche Diagnostics). The intra- and inter-assay precision CV (\%) values were $1.6-6.6 \%$ and $2.6-8.7 \%$ for $25 \mathrm{OHD}$ and $1.2-2.7 \%$ and $1.7-6.5 \%$ for PTH, respectively. The values of the lower detection limits were $3 \mathrm{ng} / \mathrm{mL}$ for $25 \mathrm{OHD}$ and $1.20 \mathrm{pg} / \mathrm{mL}$ for PTH. Ca and P were analyzed in maternal and cord blood by the NM-BAPTA and phosphomolybdate UV methods, respectively, in the Cobas Integra 400 Plus analyzer (Roche Diagnostics). Vitamin D sufficiency was defined as $25 \mathrm{OHD} \geq 30 \mathrm{ng} / \mathrm{mL}$, insufficiency as $25 \mathrm{OHD} 20-30 \mathrm{ng} / \mathrm{mL}$, and deficiency as $25 \mathrm{OHD}<20 \mathrm{ng} / \mathrm{mL}$, according to the American Endocrine Society guidelines (2).

\section{Statistical analysis}

Data were analyzed using SPSS 25.0 for Windows (IBM Corp. Released 2017, IBM SPSS Statistics for Windows, Version 25.0, IBM Corp). Data are presented as mean \pm S.D. for quantitative variables and as number (percentage) for qualitative ones. Variables were tested for normality with the Kolmogorov-Smirnov test. Comparisons between subgroups were performed using the independent samples $t$-test (normally distributed data) and the Mann-Whitney $U$ test (non-normally distributed data). Frequencies were compared with the chi-squared test. Correlations were estimated by Pearson's or Spearman's correlation tests,

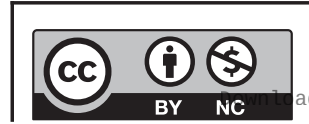

This work is licensed under a Creative Commons Attribution-NonCommercial 4.0 International License. ded from Bioscientifica.com at 04/26/2023 08:49:05AM 
as appropriate. All tests were two-tailed, and a $P$ value of less than 0.05 was considered significant.

\section{Results}

\section{Demographics and anthropometric characteristics of pregnant women and their newborns}

Our study population consisted of 103 women with a mean age of $29.2 \pm 5.3$ years. As shown in Table 1 , refugees were younger than Greeks. Most of the refugees were of Afghan origin $(n=32)$; of the rest, seven were Syrian, six were Iraqi, three Congolese, one Iranian, one Somali and one Algerian. The mean duration of gestation for all pregnant women was $38.7 \pm 1.1$ weeks without any differences between the two groups. Thirty-two women (31.1\%) were primiparous, 82 (79.6\%) delivered vaginally, while in 21 , cesarean section was performed. Interestingly, the proportion of women undergoing C-section was higher in Greeks compared to refugees. C-section was performed for the following reasons: previous C-section $(n=13)$, cephalopelvic disproportion $(n=4)$, breech position $(n=1)$, no progression of labor $(n=2)$, maternal tachycardia $(n=1)$. All newborns were healthy and were born at term. Their mean birth weight, length and head circumference were $3274.6 \pm 348.2 \mathrm{~g}, 45.6 \pm 1.7 \mathrm{~cm}$ and $34.4 \pm 1.4 \mathrm{~cm}$, respectively, without any differences between the two groups.

\section{Vitamin $\mathrm{D}$ and bone mineral homeostasis in} pregnant women of Greek origin and refugees

Comparing Greek women with refugees, we found that Greeks had higher total serum $\mathrm{Ca}$ and 25OHD and lower PTH than refugees. Umbilical cord levels of $\mathrm{Ca}$ and 25OHD were also higher, and PTH lower in Greek women as shown in Table 2. VDD was frequent in both groups but was significantly more common in refugees $(92.2$ vs $67.3 \%, P=0.003)$. Only $7.7 \%$ of the Greeks and $2 \%$ of the refugees had $25 \mathrm{OHD}$ levels $>30 \mathrm{ng} / \mathrm{mL}$, whereas $19.2 \%$ of Greeks and $70.6 \%$ of refugees had severe hypovitaminosis $\mathrm{D}(<10 \mathrm{ng} / \mathrm{mL})$. Likewise, secondary hyperparathyroidism was more prevalent in refugees. There were no statistically significant seasonal variations in serum 25OHD levels in either group (although there was a trend toward higher levels in autumn), and refugees had always lower 25OHD than Greeks, regardless of the season of delivery.

As expected, $\mathrm{Ca}$ and $\mathrm{P}$ were higher in umbilical cord than in maternal blood $(10.4 \pm 1.3 \mathrm{mg} / \mathrm{dL}$ and $5.5 \pm 0.9 \mathrm{mg} / \mathrm{dL}$ vs $8.4 \pm 1.3 \mathrm{mg} / \mathrm{dL}$ and $3.4 \pm 0.8 \mathrm{mg} / \mathrm{dL}$, respectively, $P<0.001)$. In contrast, PTH was significantly higher in the maternal circulation $(46.4 \pm 33.8 \mathrm{pg} / \mathrm{mL}$ vs $7.3 \pm 12.5 \mathrm{pg} / \mathrm{mL}$, $P<0.001)$. There was no significant difference between the maternal and umbilical cord blood levels of 25OHD $(13.5 \pm 10.9 \mathrm{ng} / \mathrm{mL}$ vs $12.8 \pm 7.8 \mathrm{ng} / \mathrm{mL}, P=0.232)$. Maternal 25OHD displayed a strong positive correlation with umbilical cord 25OHD $(\mathrm{r}=0.905, P<0.001)$ and a negative correlation with maternal PTH $(\mathrm{r}=-0.422, P<0.001)$. In addition, maternal 25OHD was positively correlated with umbilical cord $\mathrm{Ca}(\mathrm{r}=0.335, P=0.001)$ and weakly correlated with maternal Ca $(\mathrm{r}=0.185, P=0.05)$. Cord blood 25OHD demonstrated positive correlations with cord blood Ca $(\mathrm{r}=0.361, P<0.001)$ and $\mathrm{P}(\mathrm{r}=0.296, P=0.002)$. We also found that maternal $\mathrm{Ca}$ and $\mathrm{P}$ levels were positively correlated with umbilical cord $\mathrm{Ca}$ and $\mathrm{P}(\mathrm{r}=0.588, P<0.001$ for $\mathrm{Ca}$ and $\mathrm{r}=0.539, P<0.001$ for $\mathrm{P}$, respectively).

\section{Effect of vitamin D deficiency on neonatal outcomes}

Neonates born to Greek mothers demonstrated a trend for higher birth weight and length, which did not reach

Table 1 Anthropometric and clinical characteristics of pregnant women and their neonates. Greek women and refugees were compared for anthropometric characteristics (age) and clinical characteristics (gestational age in weeks and mode of delivery). Anthropometric and clinical features of their neonates were also assessed (neonatal sex, birth weight, body length and head circumference).

\begin{tabular}{l}
\hline Age (years) \\
Gestational age (weeks) \\
Mode of delivery (vaginal/cesarean section) \\
Neonatal sex (M/F) \\
Neonate birth weight $(\mathrm{g})$ \\
Neonate body length $(\mathrm{cm})$ \\
Neonate head circumference $(\mathrm{cm})$
\end{tabular}

\begin{tabular}{c}
\hline Greeks $(n=52)$ \\
\hline $31.0 \pm 4.7$ \\
$38.8 \pm 1.4$ \\
$36 / 16$ \\
$30 / 22$ \\
$3336.4 \pm 382.7$ \\
$45.9 \pm 1.5$ \\
$34.6 \pm 1.5$ \\
\hline
\end{tabular}

(5)

Refugees $(n=51)$
$27.3 \pm 5.2$
$38.5 \pm 0.8$
$46 / 5$
$25 / 26$
$3211.6 \pm 300.0$
$45.3 \pm 1.8$
$34.3 \pm 1.2$

\begin{tabular}{c}
\hline \multicolumn{1}{c}{$\boldsymbol{P}$} \\
\hline$<\mathbf{0 . 0 0 1}$ \\
0.075 \\
$\mathbf{0 . 0 0 8}$ \\
0.378 \\
0.060 \\
0.055 \\
0.224
\end{tabular}

Bold indicates statistical significance, $P<0.05$.

https://ec.bioscientifica.com

https://doi.org/10.1530/EC-21-0412 (c) 2022 The authors Published by Bioscientifica Ltd
This work is licensed under a Creative Commons Attribution-NonCommercial 4.0 International License. ded from Bioscientifica.com at 04/26/2023 08:49:05AM 
Table 2 Laboratory evaluation of pregnant women and their neonates. Greek women and refugees were evaluated for Ca, phosphate, 25OHD and PTH. Similarly, neonates were compared for umbilical cord Ca, phosphate, 25OHD and PTH.

\begin{tabular}{l}
\hline \\
\hline Maternal Ca $(\mathrm{mg} / \mathrm{dL})$ \\
Maternal P (mg/dL) \\
Maternal $25 \mathrm{OHD}(\mathrm{ng} / \mathrm{mL})$ \\
Maternal vitamin D deficiency $(n(\%))$ \\
Maternal PTH $(\mathrm{pg} / \mathrm{mL})$ \\
Secondary hyperparathyroidism $(n(\%))$ \\
Umbilical cord Ca $(\mathrm{mg} / \mathrm{dL})$ \\
Umbilical cord P $(\mathrm{mg} / \mathrm{dL}$ \\
Umbilical cord $25 \mathrm{OHD}(\mathrm{ng} / \mathrm{mL})$ \\
Umbilical cord PTH $(\mathrm{pg} / \mathrm{mL})$ \\
Neonatal vitamin D deficiency $(n(\%))$ \\
\hline
\end{tabular}

\begin{tabular}{c}
\hline Greeks $(n=52)$ \\
\hline $8.4 \pm 1.5$ \\
$3.4 \pm 0.9$ \\
$17.9 \pm 12.2$ \\
$35(67.3 \%)$ \\
$36.7 \pm 27.2$ \\
$7.7 \%$ \\
$10.8 \pm 1.3$ \\
$5.6 \pm 1.0$ \\
$16.5 \pm 6.7$ \\
$4.8 \pm 3.2$ \\
$38(73.1 \%)$ \\
\hline
\end{tabular}

\begin{tabular}{c}
\hline Refugees $(n=51)$ \\
\hline $8.2 \pm 1.0$ \\
$3.4 \pm 0.8$ \\
$9.1 \pm 7.1$ \\
$47(92.2 \%)$ \\
$56.3 \pm 37.1$ \\
$25.5 \%$ \\
$10.0 \pm 1.1$ \\
$5.4 \pm 0.8$ \\
$9.0 \pm 7.1$ \\
$9.8 \pm 17.1$ \\
$46(90.2 \%)$ \\
\hline
\end{tabular}

\begin{tabular}{r}
\hline \multicolumn{1}{c}{$\boldsymbol{P}$} \\
\hline $\mathbf{0 . 0 0 4}$ \\
0.709 \\
$<0.001$ \\
$\mathbf{0 . 0 0 3}$ \\
$<\mathbf{0 . 0 0 1}$ \\
$\mathbf{0 . 0 1 5}$ \\
$<\mathbf{0 . 0 0 1}$ \\
0.180 \\
$<\mathbf{0 . 0 0 1}$ \\
$\mathbf{0 . 0 0 1}$ \\
$\mathbf{0 . 0 4 1}$
\end{tabular}

PTH, parathyroid hormone; 25OHD, 25-hydroxyvitamin D.

Bold indicates statistical significance, $P<0.05$.

statistical significance. Head circumference did not differ between the groups. The vast majority (84/103) of newborns had VDD, which affected refugee newborns to a greater extent as shown in Table 1 . None of the newborns born to a refugee mother was vitamin D sufficient, while the respective percentage was only $3.8 \%$ among the offspring of Greek women. Finally, the birth weight of the neonates was significantly correlated with the maternal $P$ $(\mathrm{r}=0.227, P=0.021)$ and the umbilical cord $\mathrm{P}(\mathrm{r}=0.256$, $P=0.009)$ and $\mathrm{Ca}(\mathrm{r}=0.246, P=0.012)$ levels, whereas their head circumference was positively correlated with maternal 25OHD $(\mathrm{r}=0.218, P=0.027)$.

\section{Discussion}

According to the United Nations High Commissioner for Refugees, 79.5 million people around the world had been forcibly displaced from their primary residence at the end of 2019, including 26 million refugees. Refugees are constantly faced with multiple acute and chronic illnesses (14). Among them, a particularly sensitive group are women in pregnancy (15). Timely access to perinatal healthcare is the only effective method to optimize pregnancy outcomes and the lifelong health of women and their offspring (15). Late or no access to maternity care can result in adverse perinatal outcomes (15). Pregnant women with asylum seeker and refugee status face barriers to accessing healthcare (16) including maternity care (17). Previously published systematic studies report that pregnant women who are seeking asylum or are refugees demonstrate a higher prevalence of antenatal and postnatal mental disorders including depression $(18,19)$, higher maternal and neonatal mortality rates $(20,21)$, lower birth weight for their offspring (22), preterm deliveries (23) and neonatal congenital abnormalities (23) than women from their host countries.

Endocrinopathies are common diseases among women of reproductive age, and thus, pregnant women are particularly susceptible to such disorders. Even though VDD has been reported in refugees (see below), no study has addressed the prevalence of VDD in refugees during pregnancy or postpartum. In this study, we focused on investigating the prevalence and outcomes of VDD in pregnant women and their newborns who seek asylum or are refugees and compared them to Greek inhabitants for the following reasons:

(i) Greece has been one of the main host countries of refugees from the Middle East in the most recent years: The armed conflicts and the severe economic/nutritional crises affecting multiple countries of Asia and Africa since the beginning of the 20th century have generated an overwhelming refugee flow toward Europe. Due to its geographic position, Greece is the main point of entry for refugees, and several thousands of them have taken residence in the country. As refugee camps have become overcrowded, host countries are unable to meet the demands of the population in need.

(ii) VDD is highly prevalent in Greece among adults, children and pregnant women. In a study of 271 postmenopausal women (mean age: 67.3 years old) living in Athens, Greece, the mean serum 25OHD was $16.53 \pm 6.41(\mathrm{ng} / \mathrm{mL})$ (24). Similarly, when 393 pre-school children living in Greece were studied, $6.6 \%$ of them had serum 25OHD less than $10 \mathrm{ng} / \mathrm{mL}$ with immigrant children demonstrating lower serum 25OHD levels associated with lower

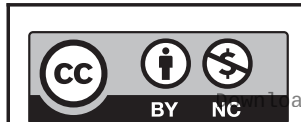

This work is licensed under a Creative Commons Attribution-NonCommercial 4.0 International License. ded from Bioscientifica.com at 04/26/2023 08:49:05AM via free access 
vitamin D intake and lower socioeconomic class when compared with the Greek children (25). In addition, in a study that included 23 healthy mother-newborn pairs living in Athens, Greece, $19.5 \%$ of the mothers and $8.1 \%$ of the neonates had a $25 \mathrm{OHD}$ level less than $10 \mathrm{ng} / \mathrm{mL}(11)$.

(iii) VDD is one of the most prevalent conditions among adult and child refugees around the world: In Canada, VDD/vitamin D insufficiency was shown to affect half of the immigrant children included in a study, while it was even more common (70-80\%) in refugee children $(26,27)$. Similar results have been obtained in European countries, where $76-86 \%$ of refugees arriving in Denmark and Switzerland are vitamin D deficient $(28,29)$, while the mean $25 \mathrm{OHD}$ levels of 46 studied refugees in Italy was $9.18 \mathrm{ng} / \mathrm{mL}$ (30). Finally, $77.5 \%$ of 3307 refugees arriving to Sydney, Australia, were found to have VDD (42.7\% mild, 32.6\% moderate and $2.3 \%$ severe); interestingly, more than $75 \%$ of the study population was from Middle Eastern countries (31).

In our study, we found that that maternal VDD was frequent in both Greeks and refugees at delivery, but it was significantly more common in refugees (92.2 vs $67.3 \%, P=0.003)$. Importantly, $70.6 \%$ of refugees had severe hypovitaminosis D (<10 ng/mL). Greeks had higher total serum $\mathrm{Ca}$ and 25OHD and lower PTH than refugees. Umbilical cord levels of Ca and 25OHD were also higher, and PTH lower in Greek women compared to refugees. Even though in normal pregnancy PTH decreases compared to pre-pregnancy levels (5), secondary hyperparathyroidism was detected in both groups but was more prevalent in refugees, highlighting the severity of VDD in this group. Although in the present study factors known to determine vitamin D status (sun exposure, dietary intake, etc.) were not evaluated, there are several possible explanations for the observed difference in $25 \mathrm{OHD}$ between the two groups. First, all Greek women are advised to use vitamin D supplementation at $800 \mathrm{IU} /$ day, whereas none of the refugees were taking vitamin $\mathrm{D}$ supplements. In addition, Greeks exhibit different lifestyle practices regarding clothing, which allow for greater exposure to sunlight. Moreover, low socio-demographic status of recent immigrants with chronic dietary insufficiencies of $\mathrm{Ca}$ and vitamin D may result in further restriction of vitamin D synthesis or vitamin $\mathrm{D}$ intake. This fact may be related to lack of knowledge regarding vitamin D requirements in the new environment, dietary habits established in country of origin, low income that limits healthy dietary choices and lack of access to supplements as well as lifestyle habits that limit exposure to sunlight.

Vitamin D sufficiency is crucial during pregnancy as well as postnatally for both the mother and the neonate. The normal development of the fetal/neonatal skeleton requires significant amounts of minerals, mainly $\mathrm{Ca}$ and phosphate. While in utero, these are provided by the maternal circulation through the placenta; maternal levels of 1,25OH-VitD double early in pregnancy leading to increased intestinal absorption of $\mathrm{Ca}$ and phosphate, in order to cover fetal demand. Interestingly, the fetal blood $\mathrm{Ca}$ is regulated relatively independently of the levels of maternal $\mathrm{Ca}$ and vitamin $\mathrm{D}$, with the fetus always having a higher than maternal level, due to the regulatory role of PTH-related peptide (5). The importance of vitamin D becomes apparent postnatally, as the neonate depends solely on vitamin D-mediated intestinal absorption of Ca and phosphate to supply its developing skeleton, and the only physiological source of vitamin $\mathrm{D}$ for the neonate is the maternally derived 25OHD stored during pregnancy. Hence, in the early postnatal period, the neonatal Ca level depends on the maternal 25OHD, as shown in both animals and humans: Studies of maternal VDD in rats $(32,33,34)$ and pigs (33) have shown that the blood $\mathrm{Ca}$ is typically normal at birth and the skeleton is fully mineralized, but later on, neonates develop hypocalcemia, rachitic skeletal lesions and failure to thrive $(34,35)$. Similarly, in humans, low 25OHD levels in neonatal or cord blood have been associated with hypocalcemia (6), rachitic changes in the skull (36) and decreased wrist ossification (37) in infants. Conversely, vitamin D supplementation during pregnancy is associated with higher neonatal serum Ca levels and a reduced incidence of neonatal hypocalcemia and skeletal defects $(34,38)$. These findings suggest that maternal/fetal VDD may be manifest early in postnatal life. In addition, maternal VDD has been associated with increased health risks in the offspring in later life (e.g. childhood obesity), through epigenetic modifications (10). Thus, careful preand postnatal screening of mothers and their offspring is highly recommended to prevent adverse outcomes. Furthermore, in selected populations where VDD is highly prevalent and screening might be impractical for many reasons such as in pregnant refugees, providing adequate Vitamin D supplementation upon initial medical contact could be a cheaper, faster and more reliable strategy to mitigate the risks of maternal VDD.

In our study, we showed that the vast majority of newborns had VDD, which affected refugee newborns to a greater extent (none of the refugee newborns were vitamin D sufficient). Neonatal head circumference was 
positively correlated with maternal 25OHD. The association of vitamin D levels with neonatal anthropometric characteristics has been supported by prior studies. In a population-based birth cohort study that recruited 3658 eligible mother-and-singleton-offspring pairs, a positive correlation between maternal serum 25OHD level and offspring birth weight was observed (39). Moreover, in a metanalysis that included 54 eligible studies, vitamin D-deficient mothers ( $<30 \mathrm{nmol} / \mathrm{L})$ had offspring with lower birthweight, lower head circumference and a higher risk of small for gestational age infants and preterm birth compared to mothers with concentrations $\geq 30 \mathrm{nmol} / \mathrm{L}$. Importantly, offspring of vitamin D-insufficient mothers had lower scores in mental and language developmental tests, highlighting the potential long-term outcomes of VDD (40). We also found that the newborn's birthweight was positively correlated with cord blood $\mathrm{Ca}$ and phosphate levels. Previous works have revealed similar correlations: in a study of 223 women with live-born singleton deliveries from rural Bangladesh, birth length exhibited a significant relationship with cord blood Ca, even after adjusting for several covariates (gestational age, sex of newborn, socioeconomic status, maternal height, BMI, age and season at birth) (41). Furthermore, in a study of 70 pregnant women and their neonates, cord blood Ca levels were significantly positively correlated with birth weight, birth length and head circumference, whereas cord P was significantly positively correlated with birth length (42).

Limitations of the study included the following: (i) no dedicated questionnaires assessing the clothing or sun exposure (that information was gathered only through medical history) were available; (ii) even though Greek pregnant women were advised to take 800 IU of vitamin $\mathrm{D}$ daily, their adherence to supplementation is not clear as it was not systematically documented in each visit; (iii) even though total protein was measured and no hypoproteinemia was identified, no albumin levels were checked and thus we could not correct Ca for albumin. Thus, total Ca was assessed and compared between the groups; (iv) the groups of women studied (Greek women vs refugees) have different ethnic backgrounds, and thus, cultural practices and diet may have influenced the outcomes. In addition, the refugee population that remain on the island of Lesbos may be rather different from those refugees that are able to move on from the island. Further studies in subgroups of refugee populations are required to evaluate such cultural and socioeconomic factors on the prevalence of VDD; (v) finally, long-term follow-up of neonates was not performed in the current study, as recall for re-assessment of refugees and their neonates has been limited due to the difficult living conditions.

In conclusion, to our knowledge, this is the first study that has investigated the prevalence of VDD in refugee pregnant women and the associated outcomes in their newborns. We discovered high prevalences of VDD in both Greek inhabitants and refugees. Seventy percent (70\%) of refugees display severe hypovitaminosis compared to $19.2 \%$ of Greek women. As a result, most newborns had VDD, which affected refugee newborns more severely than Greek neonates. VDD can lead to devastating health outcomes for both mothers and neonates, and thus, prenatal education, screening, adequate supplementation and monitoring are fundamental ways of improving the outcome in such vulnerable populations. Our results suggest a need to screen newcomer children and pregnant women for VDD in all host countries around the world. Such a screen will appropriately guide early and effective interventions. Importantly, in countries where VDD is highly prevalent and screening can be cost- and timeeffective, acting upon this situation at the population level with adequate vitamin D supplementation of pregnant refugees upon their first contact with healthcare providers might be recommended.

\section{Declaration of interest}

The authors declare that there is no conflict of interest that could be perceived as prejudicing the impartiality of the research reported.

\section{Funding}

This work did not receive any specific grant from any funding agency in the public, commercial or not-for-profit sector.

\section{References}

1 Holick MF. Vitamin D deficiency. New England Journal of Medicine 2007 357 266-281. (https://doi.org/10.1056/NEJMra070553)

2 Holick MF, Binkley NC, Bischoff-Ferrari HA, Gordon CM, Hanley DA, Heaney RP, Murad MH, Weaver CM \& Endocrine Society. Evaluation, treatment, and prevention of vitamin D deficiency: an Endocrine Society clinical practice guideline. Journal of Clinical Endocrinology and Metabolism 201196 1911-1930. (https://doi.org/10.1210/jc.20110385)

3 Garland CF, Garland FC, Gorham ED, Lipkin M, Newmark H, Mohr SB \& Holick MF. The role of vitamin D in cancer prevention. American Journal of Public Health 200696 252-261. (https://doi.org/10.2105/ AJPH.2004.045260)

4 Yang CY, Leung PS, Adamopoulos IE \& Gershwin ME. The implication of vitamin D and autoimmunity: a comprehensive review. Clinical Reviews in Allergy and Immunology 201345 217-226. (https://doi. org/10.1007/s12016-013-8361-3)

5 Kovacs CS \& Kronenberg HM. Maternal-fetal calcium and bone metabolism during pregnancy, puerperium, and lactation. Endocrine Reviews 199718 832-872. (https://doi.org/10.1210/edrv.18.6.0319) 
6 Specker BL. Do North American women need supplemental vitamin D during pregnancy or lactation? American Journal of Clinical Nutrition 199459 (2 Supplement) 484S-490S; discussion 490S-491S. (https:// doi.org/10.1093/ajcn/59.2.484S)

7 Zhang MX, Pan GT, Guo JF, Li BY, Qin LQ \& Zhang ZL. Vitamin D deficiency increases the risk of gestational diabetes mellitus: a metaanalysis of observational studies. Nutrients 20157 8366-8375. (https:// doi.org/10.3390/nu7105398)

8 Shibata M, Suzuki A, Sekiya T, Sekiguchi S, Asano S, Udagawa Y \& Itoh M. High prevalence of hypovitaminosis D in pregnant Japanese women with threatened premature delivery. Journal of Bone and Mineral Metabolism 201129 615-620. (https://doi.org/10.1007/s00774011-0264-x)

9 Scholl TO, Chen X \& Stein P. Maternal vitamin D status and delivery by cesarean. Nutrients 20124 319-330. (https://doi.org/10.3390/ nu4040319)

10 Godfrey KM, Costello PM \& Lillycrop KA. Development, epigenetics and metabolic programming. Nestle Nutrition Institute Workshop Series 201685 71-80. (https://doi.org/10.1159/000439488)

11 Nicolaidou P, Hatzistamatiou Z, Papadopoulou A, Kaleyias J, Floropoulou E, Lagona E, Tsagris V, Costalos C \& Antsaklis A. Low vitamin D status in mother-newborn pairs in Greece. Calcified Tissue International 200678 337-342. (https://doi.org/10.1007/s00223-0060007-5)

12 Papapetrou PD, Triantaphyllopoulou M, Karga H, Zagarelos P, Aloumanis K, Kostakioti E \& Vaiopoulos G. Vitamin D deficiency in the elderly in Athens, Greece. Journal of Bone and Mineral Metabolism 200725 198-203. (https://doi.org/10.1007/s00774-006-0746-4)

13 Lips P \& de Jongh RT. Vitamin D deficiency in immigrants. Bone Reports 20189 37-41. (https://doi.org/10.1016/j.bonr.2018.06.001)

14 Kumar GS, Beeler JA, Seagle EE \& Jentes ES. Long-term physical health outcomes of resettled refugee populations in the United States: a scoping review. Journal of Immigrant and Minority Health 202123 813-823. (https://doi.org/10.1007/s10903-021-01146-2)

15 Heslehurst N, Brown H, Pemu A, Coleman H \& Rankin J. Perinatal health outcomes and care among asylum seekers and refugees: a systematic review of systematic reviews. BMC Medicine 20181689 (https://doi.org/10.1186/s12916-018-1064-0)

16 Cheng IH, Drillich A \& Schattner P. Refugee experiences of general practice in countries of resettlement: a literature review. British Journal of General Practice 201565 e171-e176. (https://doi.org/10.3399/ bjgp15X683977)

17 Khanlou N, Haque N, Skinner A, Mantini A \& Kurtz Landy C. Scoping review on maternal health among immigrant and refugee women in Canada: prenatal, intrapartum, and postnatal care. Journal of Pregnancy 20172017 8783294. (https://doi. org/10.1155/2017/8783294)

18 Fellmeth G, Fazel M \& Plugge E. Migration and perinatal mental health in women from low- and middle-income countries: a systematic review and meta-analysis. BJOG 2017 124 742-752. (https:// doi.org/10.1111/1471-0528.14184)

19 Schmied V, Black E, Naidoo N, Dahlen HG \& Liamputtong P. Migrant women's experiences, meanings and ways of dealing with postnatal depression: a meta-ethnographic study. PLoS ONE 201712 e0172385. (https://doi.org/10.1371/journal.pone.0172385)

20 Pedersen GS, Grontved A, Mortensen LH, Andersen AM \& RichEdwards J. Maternal mortality among migrants in Western Europe: a meta-analysis. Maternal and Child Health Journal 201418 1628-1638. (https://doi.org/10.1007/s10995-013-1403-x)

21 Gissler M, Alexander S, MacFarlane A, Small R, Stray-Pedersen B, Zeitlin J, Zimbeck M \& Gagnon A. Stillbirths and infant deaths among migrants in industrialized countries. Acta Obstetricia et Gynecologica Scandinavica 200988 134-148. (https://doi. org/10.1080/00016340802603805)

22 Kelaher M \& Jessop DJ. Differences in low-birthweight among documented and undocumented foreign-born and US-born
Latinas. Social Science and Medicine 200255 2171-2175. (https://doi. org/10.1016/s0277-9536(01)00360-4)

23 Bollini P, Pampallona S, Wanner P \& Kupelnick B. Pregnancy outcome of migrant women and integration policy: a systematic review of the international literature. Social Science and Medicine 200968 452-461. (https://doi.org/10.1016/j.socscimed.2008.10.018)

24 Kyriakaki A \& Fragkoulis E. The vitamin D paradox: high prevalence of deficiency in sunny Athens (Greece) Annals of Research Hospitals 20193 13-13. (https://doi.org/10.21037/arh.2019.06.02)

25 Nicolaidou PK, Kakourou T, Papadopoulou A, Kavadias G, Dimitriou E, Georgouli H, Tsapra H, Giannoulia-Karantana A, Fretzayas A, Tsiftis $\mathrm{G}$, et al. Low vitamin D status in preschool children in Greece. Nutrition Research 200626 620-625. (https://doi.org/10.1016/j. nutres.2006.09.018)

26 Lane G, Nisbet C, Whiting SJ \& Vatanparast H. Canadian newcomer children's bone health and vitamin D status. Applied Physiology, Nutrition and Metabolism 201944 796-803. (https://doi.org/10.1139/ apnm-2018-0705)

27 Taseen K \& Beaulieu G. Vitamin D levels and influencing predictors in refugee children in Sherbrooke (Quebec), Canada. Paediatrics and Child Health 201722 307-311. (https://doi.org/10.1093/pch/pxx092)

28 Chernet A, Hensch NP, Kling K, Sydow V, Hatz C, Paris DH, Rentsch K, Nickel B, Neumayr A \& Labhardt ND. Serum 25-hydroxyvitamin D levels and intramuscular vitamin D3 supplementation among Eritrean migrants recently arrived in Switzerland. Swiss Medical Weekly 2017147 w14568. (https://doi. org/10.4414/smw.2017.14568)

29 Andersen MH, Kruse A, Frederiksen HW, Ahmadi A \& Norredam M. Health status of refugees newly resettled in Denmark. Danish Medical Journal 202067 A08200567.

30 De Filippis LG, Trombetta I, Novella T \& Alampi M. Vitamin D deficiency in refugees in Italy. Reumatismo 201769 101-104. (https:// doi.org/10.4081/reumatismo.2017.991)

31 Ngo CC, Maidment C, Atkins L, Eagar S \& Smith MM. Blood screen findings in a 2-year cohort of newly arrived refugees to Sydney, Australia. Public Health Research and Practice 201828 2811804. (https:// doi.org/10.17061/phrp2811804)

32 Brommage R \& DeLuca HF. Placental transport of calcium and phosphorus is not regulated by vitamin D. American Journal of Physiology 1984246 F526-F529. (https://doi.org/10.1152/ ajprenal.1984.246.4.F526)

33 Lachenmaier-Currle U \& Harmeyer J. Placental transport of calcium and phosphorus in pigs. Journal of Perinatal Medicine 198917 127-136. (https://doi.org/10.1515/jpme.1989.17.2.127)

34 Halloran BP \& De Luca HF. Effect of vitamin D deficiency on skeletal development during early growth in the rat. Archives of Biochemistry and Biophysics 1981209 7-14. (https://doi.org/10.1016/00039861(81)90251-4)

35 Miller SC, Halloran BP, DeLuca HF \& Jee WS. Studies on the role of vitamin D in early skeletal development, mineralization, and growth in rats. Calcified Tissue International 198335 455-460. (https://doi. org/10.1007/BF02405076)

36 Reif S, Katzir Y, Eisenberg Z \& Weisman Y. Serum 25-hydroxyvitamin D levels in congenital craniotabes. Acta Paediatrica Scandinavica 198877 167-168. (https://doi.org/10.1111/j.1651-2227.1988.tb10620.x)

37 Specker BL, Ho ML, Oestreich A, Yin TA, Shui QM, Chen XC \& Tsang RC. Prospective study of vitamin D supplementation and rickets in China. Journal of Pediatrics 1992120 733-739. (https://doi. org/10.1016/s0022-3476(05)80236-7)

38 Brooke OG, Brown IR, Bone CD, Carter ND, Cleeve HJ, Maxwell JD, Robinson VP \& Winder SM. Vitamin D supplements in pregnant Asian women: effects on calcium status and fetal growth. BMJ $1980 \mathbf{2 8 0}$ 751-754. (https://doi.org/10.1136/bmj.280.6216.751)

39 Chen YH, Fu L, Hao JH, Yu Z, Zhu P, Wang H, Xu YY, Zhang C, Tao FB $\&$ Xu DX. Maternal vitamin D deficiency during pregnancy elevates the risks of small for gestational age and low birth weight infants in

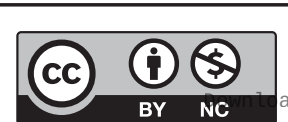

This work is licensed under a Creative Commons Attribution-NonCommercial 4.0 International License. ded from Bioscientifica.com at 04/26/2023 08:49:05AM 
Chinese population. Journal of Clinical Endocrinology and Metabolism 2015100 1912-1919. (https://doi.org/10.1210/jc.2014-4407)

40 Tous M, Villalobos M, Iglesias L, Fernandez-Barres S \& Arija V. Vitamin D status during pregnancy and offspring outcomes: a systematic review and meta-analysis of observational studies. European Journal of Clinical Nutrition 202074 36-53. (https://doi.org/10.1038/s41430-0180373-x)
41 Doi M, Rekha RS, Ahmed S, Okada M, Roy AK, El Arifeen S, Ekström EC, Raqib R \& Wagatsuma Y. Association between calcium in cord blood and newborn size in Bangladesh. British Journal of Nutrition 2011106 1398-1407. (https://doi.org/10.1017/S0007114511001747)

42 Colak A, Yildiz O, Toprak B, Turkon H, Halicioglu O \& Coker I.

Correlation between calcium and phosphorus in cord blood and birth size in term infants. Minerva Pediatrica 201668 182-188.

Received in final form 18 November 2021

Accepted 3 December 2021

Accepted Manuscript published online 3 December 2021
This work is licensed under a Creative Commons Attribution-NonCommercial 4.0 International License. 